I. Conget $\cdot$ E. Aguilera $\cdot$ S. Pellitero $\cdot$ S. Näf $\cdot$

K. Bendtzen - R. Casamitjana $\cdot$ R. Gomis $\cdot$ F. Nicoletti

\title{
Lack of effect of intermittently administered sodium fusidate in patients with newly diagnosed type 1 diabetes mellitus: the FUSIDM trial
}

Received: 4 January 2005 / Accepted: 30 March 2005 / Published online: 2 July 2005

(C) Springer-Verlag 2005

\begin{abstract}
Aims/hypothesis: We evaluated in a double-blind study the effect of early treatment with the immunomodulatory drug fusidin in patients with newly diagnosed type 1 diabetes mellitus. Methods: Twenty-eight adults with newly diagnosed type 1 diabetes were included in the study. The patients were randomly assigned (computergenerated random number sequence) to two experimental groups. Patients allocated to the fusidin (FUS) group $(n=15)$ received sodium fusidate (fusidin; $500 \mathrm{mg}$ orally three times daily for 4 weeks). Subsequently the drug was given at the same dose and scheduled for two consecutive weeks a month followed by 2 weeks a month without the drug for 20 weeks. Subjects allocated to the placebo (PCB) group $(n=13)$ received placebo according to the same schedule and conditions described for sodium fusidate in the FUS group. All patients received a diet adjusted to their age and BMI, and intensive insulin therapy. Results: There were no statistically significant differences between the FUS and PCB groups in beta cell function, evaluated by basal and
\end{abstract}

\footnotetext{
I. Conget $(\bowtie) \cdot$ E. Aguilera $\cdot$ S. Pellitero

S. Näf $\cdot$ R. Gomis

Endocrinology and Diabetes Unit,

Hospital Clínic,

Villarroel 170,

08036 Barcelona, Spain

e-mail: iconget@clinic.ub.es

Tel.: +34-93-2279846

Fax: $+34-93-4516638$

K. Bendtzen

Institute for Inflammation Research (IIR),

Rigshospitalet National University Hospital,

Copenhagen, Denmark

R. Casamitjana

Hormonology Unit,

Hospital Clinic,

Barcelona, Spain

F. Nicoletti

Department of Biomedical Sciences,

University of Catania,

Catania, Italy
}

glucagon-stimulated C-peptide values during the follow-up ( 24 and 48 weeks). There was also no difference between the two groups in insulin requirement after 48 weeks $(0.4 \pm$ 0.2 and $0.4 \pm 0.2 \mathrm{U} / \mathrm{kg}$ body weight for the FUS and PCB groups, respectively). Antibody titres, including insulin autoantibodies, were similar in the two groups during the follow-up. Conclusions/interpretation: Early treatment of newly diagnosed type 1 diabetes patients with intermittently administered fusidin failed to influence the natural course of the disease.

Keywords Fusidin - Immunotherapy - Type 1 diabetes

Abbreviations CyA: cyclosporin A - FUS: fusidin . MLDSZ: multiple low doses of streptozotocin - PCB: placebo

\section{Introduction}

Intervention trials shortly after the onset of type 1 diabetes with the aim of preserving beta cell function represent an important line of research to allow better management of type 1 diabetes patients (reviewed in [1]). In fact, the retention of a higher degree of beta cell function may lead to better metabolic control as well as reduction of hypoglycaemic episodes and microvascular complications. In addition, the results obtained from these experimental approaches could be translated into prophylactic strategies aimed at altering the natural history of the disease in the prediabetic phase.

In this context, different attempts at immune intervention have been assessed over several decades. For example, double-blind studies with the T-cell immunosuppressant cyclosporin A (CyA) have demonstrated its beneficial effect and underscored the pathogenic role of the immune system in most cases of human type 1 diabetes [1]. However, the side effects of CyA have limited its routine use in the clinical setting for newly diagnosed type 1 diabetes patients. Several efforts have therefore been made to identify immunomodulatory compounds with lower toxic- 
ity that might be considered for treatment of patients with newly diagnosed type 1 diabetes and even for prevention in individuals at risk of developing type 1 diabetes.

The antibiotic fusidic acid is a tetracyclic triterpenoic acid originally isolated from a strain of Fusidium coccineum; its prime use has been in the treatment of staphylococcal infections (reviewed in [2]). During the last decade several studies by ourselves and others have repeatedly shown that fusidic acid and its sodium salt, sodium fusidate (Leo Pharma, Ballerup, Denmark), exert powerful immunomodulatory properties both in vitro and in vivo $[2,3]$. The drug downregulates IL-2, IFN- $\gamma$ and IL-1 secretion and also inhibits the lymphocyte costimulatory activity of IL-6 and IL-1 [2,3]. The interference of fusidin with the cytokine network has been ascribed to its capacity to protect beta cells from destruction and to its observed beneficial effects in the three most commonly used preclinical models of human type 1 diabetes: the NOD mouse [4], the DP-BB rat $[2,5,6]$ and the mouse made diabetic with multiple low doses of streptozotocin (MLDSZ) [7]. These preclinical studies were corroborated by the beneficial effects of fusidin treatment in an open study conducted in newly diagnosed type 1 diabetes patients [8]. These observations, along with the fact that fusidin has been used for many years as an antibiotic with only negligible and reversible side effects, prompted us to test fusidin as a strategy to preserve beta cell function shortly after onset of type 1 diabetes in a double-blind, placebo-controlled design.

\section{Subjects and methods}

Patients and experimental groups

Thirty-four adults with newly diagnosed type 1 diabetes were assessed for eligibility. Six were excluded (two did not meet inclusion criteria, four refused to participate) and 28 were admitted to the Endocrinology and Diabetes Unit, Hospital Clínic, Barcelona. The study protocol was approved by the Hospital Clínic i Universitari ethics committee and informed consent was obtained from all patients. Criteria for inclusion were the presence of newly diagnosed type 1 diabetes according to the American Diabetes Association criteria and age $\geq 18$ and $<35$ years at the time of diagnosis. After correction of initial metabolic disturbances and immediately before discharge, subjects were randomly assigned (using a computer-generated random number sequence) to two experimental groups: FUS $(n=15)$ and PCB $(n=13)$. Patients allocated to the FUS group received sodium fusidate (Leo Pharma, Ballerup, Denmark), $500 \mathrm{mg}$ orally three times daily for 4 weeks. Subsequently the drug was given at the same dose and for two consecutive weeks each month followed by 2 weeks without the drug each month, for 20 weeks. Subjects allocated to the PCB group received placebo according to the schedule and conditions described for sodium fusidate in the FUS group. All patients received a diet adjusted for their age and BMI, and intensive insulin therapy. This dose of FUS was chosen on the basis of open pilot studies showing that similar doses of the drug favourably influenced the course of other immunoinflammatory diseases, such as Behçet's colitis, chronic endogenous uveitis, Crohn's disease (reviewed in [2]), Guillain-Barré syndrome [9] and steroid-resistant relapses of multiple sclerosis [10]. The drug was administered intermittently to avoid the possible emergence of drugrelated toxicities secondary to its prolonged use, as there was no available information on the possible side effects of continuous 6-month treatment with $1.5 \mathrm{~g}$ FUS/day.

\section{Intensive insulin therapy}

The intensive insulin therapy schedule consisted of three or four daily doses of insulin s.c., as required: rapid-acting insulin before meals and NPH insulin before dinner/bedtime. Insulin doses were adjusted in every patient to maintain the preprandial blood glucose level between 3.9 and $7.0 \mathrm{mmol} / \mathrm{l}$ and the postprandial glucose level $<10$ $\mathrm{mmol} / \mathrm{l}$, based on four to six daily capillary determinations. During the admission period all patients were included in a 5-day education programme for patients with newly diagnosed type 1 diabetes.

\section{Assessment of pancreatic beta-cell function}

A glucagon test was performed in the absence of hypoglycaemia in the previous $48 \mathrm{~h}$ and only when fasting blood glucose values were between 5.0 and $8.0 \mathrm{mmol} / \mathrm{l}$. Plasma C-peptide measurements were performed before and $6 \mathrm{~min}$ after i.v. injection of $1 \mathrm{mg}$ of glucagon (NovoNordisk, Gentofte, Denmark). C-peptide was determined by RIA (limit of detection $0.033 \mathrm{nmol} / \mathrm{l}$; intra-assay CV 2.6\%; interassay CV 4.4\%) and a commercially available kit (Bick Santeg, Dietzenbach, Germany). Basal and stimulated C-peptide concentrations during the glucagon test were used as beta cell function parameters.

\section{Antibody measurements}

Glutamic acid decarboxylase, tyrosine phosphatase antibodies and insulin autoantibodies were measured as described previously [11].

\section{Follow-up}

The same team visited patients every 2 weeks during the first 12 weeks, and then at 24, 36 and 48 weeks. At each visit weight, daily insulin dose, hypoglycaemic episodes and adverse events were recorded and patients were reinstructed in the glucose goals. The glucagon test and antibody measurements were performed initially and after 24 and 48 weeks. $\mathrm{HbA}_{1} \mathrm{c}$ was determined by HPLC (HA 8121, Menarini Diagnostici, Firenze, Italy) at the same intervals (normal range $3.4-5.5 \%$ ). 
Statistical analysis

Data are presented as mean $\pm \mathrm{SD}$ unless stated otherwise. Thirteen patients were considered to be included in each of the two treatment groups to detect a $50 \%$ difference in stimulated C-peptide at the end of the study, with a twotailed alpha value of 0.05 and $1-$ beta $=80 \%$ (projected value of stimulated C-peptide after 48 weeks in the control group, $1.12 \mathrm{ng} / \mathrm{ml}$ ). Baseline comparisons between the two groups were performed using the Mann-Whitney test. Changes over time in the same group were evaluated with the Wilcoxon signed rank test. Comparison of the treatment effect between experimental groups for the changes in the primary outcome was performed with the Mann-Whitney test. Comparisons between proportions were done with exact Fisher's test. A $p$ value $<0.05$ was considered statistically significant. All statistical calculations were performed with the Statistical Package for Social Science software (version 10.0, SPSS, Chicago, IL, USA) for personal computers.

\section{Results}

Twenty-eight subjects were included in the study. Two subjects in the PCB group and three in the FUS group were excluded because of early lack of compliance with the protocol. Only one subject was excluded (PCB group) from the intention-to-treat analysis because of no postrandomisation data on primary and secondary endpoints. The intention-to-treat analysis included 15 subjects in the FUS group and 12 in the PCB group. The clinical characteristics of the two experimental groups are shown in Table 1.

In general, $\mathrm{HbA}_{1} \mathrm{c}$ values declined towards normal values shortly after treatment was initiated in both groups.

Table 1 Baseline characteristics of the study groups

\begin{tabular}{lll}
\hline & FUS & PCB \\
\hline Number of subjects & 15 & 12 \\
Age (years) & $26.5 \pm 5.6$ & $28.1 \pm 4.6$ \\
Sex (male/female) $(n)$ & $7 / 8$ & $8 / 4$ \\
BMI $\left(\mathrm{kg} / \mathrm{m}^{2}\right)$ & $22.5 \pm 4.3$ & $21.3 \pm 2.8$ \\
$\mathrm{HbA}_{1} \mathrm{c}(\%)$ & $10.6 \pm 3.1$ & $10.3 \pm 2.1$ \\
Weeks to diagnosis $^{\mathrm{a}}$ & $10.1 \pm 2.8$ & $6.8 \pm 4.3$ \\
$\mathrm{H} / \mathrm{K} / \mathrm{DKA}(n)$ & $2 / 9 / 4$ & $1 / 8 / 3$ \\
Any antibody positive $(\%)$ & 93 & 92 \\
Basal C-peptide $(\mathrm{ng} / \mathrm{ml})$ & $0.62 \pm 0.32$ & $0.67 \pm 0.39$ \\
Stimulated C-peptide $(\mathrm{ng} / \mathrm{ml})$ & $1.20 \pm 0.78$ & $1.54 \pm 0.82$ \\
\hline
\end{tabular}

Data are means $\pm \mathrm{SD}$, unless otherwise stated

Ketosis was defined when hyperglycaemia was associated with ketonuria (ketone bodies in urine $>15 \mathrm{mmol} / \mathrm{l}$; nitroprusside reaction method) without diabetic ketoacidosis (DKA). DKA was considered when plasma glucose $>13.9-16.7 \mathrm{mmol} / \mathrm{l}$, arterial $\mathrm{pH}$ $<7.25$, serum bicarbonate $<15 \mathrm{mEq} / 1$ and ketonuria $>15 \mathrm{mmol} / \mathrm{l}$ FUS group receiving fusidin, $P C B$ group receiving placebo, $H / K /$ $D K A$ hyperglycaemia/ketosis/diabetic ketoacidosis

${ }^{a}$ Weeks of symptoms before diagnosis and initial treatment at hospital
Table 2 Basal and stimulated C-peptide during the follow-up

\begin{tabular}{llll}
\hline & FUS & PCB & $p$ value \\
\hline 24 weeks & & & \\
Basal C-peptide (ng/ml) & $0.67 \pm 0.43$ & $0.97 \pm 0.47$ & 0.11 \\
Stimulated C-peptide (ng/ml) & $1.20 \pm 0.78$ & $1.54 \pm 0.82$ & 0.28 \\
48 weeks & & & \\
Basal C-peptide (ng/ml) & $0.67 \pm 0.32$ & $0.70 \pm 0.29$ & 0.86 \\
Stimulated C-peptide (ng/ml) & $1.02 \pm 0.48$ & $1.15 \pm 0.60$ & 0.79 \\
\hline
\end{tabular}

Data are means \pm SD

FUS group receiving fusidin; $P C B$ group receiving placebo

They were not significantly different at any time of the follow-up (24 weeks, $5.8 \pm 1.1$ and $5.3 \pm 0.6 \%$; 48 weeks, $5.8 \pm 0.9$ and $5.8 \pm 1.1 \%$; FUS and PCB groups, respectively). None of the patients included in the protocol experienced severe hypoglycaemic episodes requiring assistance during the follow-up. There were no adverse events related to the administration of either placebo or sodium fusidate, the latter being well tolerated throughout the study. After 48 weeks of treatment, weight increased similarly in both groups (FUS group, from $65.1 \pm 10.6 \mathrm{~kg}$ at entry to $69.8 \pm 11.8 \mathrm{~kg}$ at 48 weeks; PCB group, from $67.0 \pm 8.9 \mathrm{~kg}$ at entry to $73.8 \pm$

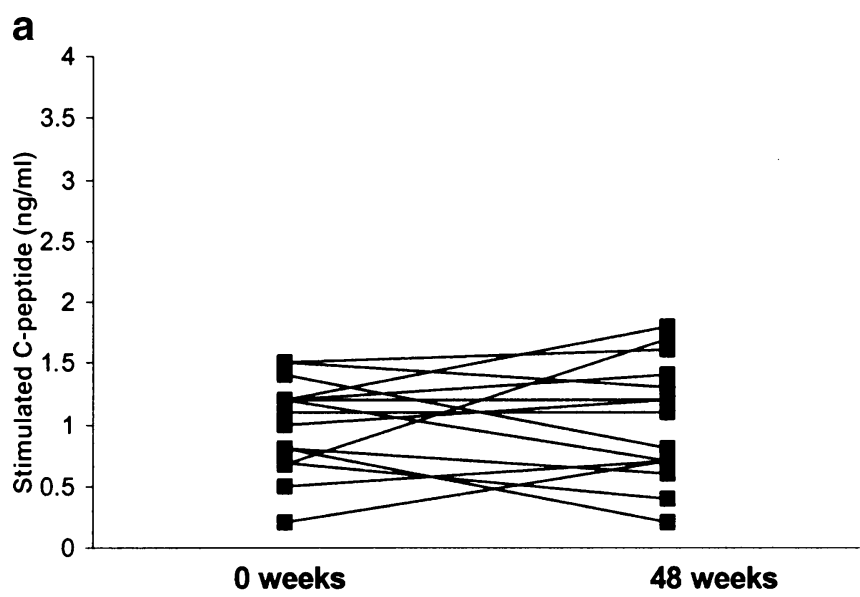

b

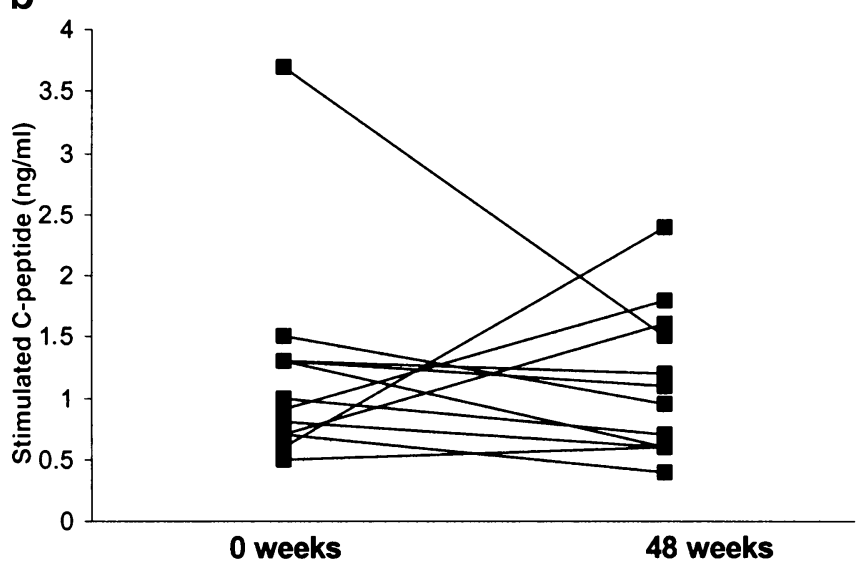

Fig. 1 Stimulated C-peptide at entry and at the end of the study in each individual subject. a Group receiving fusidin. b Group receiving placebo 
$10.3 \mathrm{~kg}$ at 48 weeks). There were no differences between the groups in terms of beta cell function evaluated from basal and glucagon-stimulated C-peptide values during follow-up (Table 2). This was also the case for insulin requirement: $0.4 \pm 0.2 \mathrm{U} / \mathrm{kg}$ body weight in the FUS group and $0.4 \pm 0.2 \mathrm{U} / \mathrm{kg}$ body weight in the PCB group. As shown in Fig. 1, beta cell function remained mostly unchanged after 48 weeks of follow-up in both groups. The number of subjects with an increase $>50 \%$ in stimulated C-peptide after 48 weeks in comparison with initial value was three in both groups. Antibody titres were similar in both groups during the follow-up, including those for insulin autoantibodies.

\section{Discussion}

Our study failed to demonstrate a beneficial effect of intermittently adding fusidin to intensive insulin therapy in patients with newly diagnosed type 1 diabetes, both in terms of beta cell function and metabolic control. Hence, these data do not support the results of our previous pilot study, a non-randomised trial in which early institution of fusidin treatment increased the rate of complete remission in newly diagnosed type 1 diabetes patients compared with untreated controls. It is, however, difficult to compare the two studies because of major differences in the design, treatment regimens and primary aims. In the pilot trial, fusidin was administered at the dose of $2 \mathrm{~g} /$ day until the onset of clinical remission (defined by suspension of insulin therapy and normal blood glucose levels) or until 2 months of continuous medication. In the present study, the drug was given at the dose of $1.5 \mathrm{~g} /$ day, commencing with continuous treatment for 4 weeks, followed by alternating periods of 2 weeks with and 2 weeks without treatment. In addition, fusidin was administered along with intensive insulin therapy and, according to more recent treatment guidelines on the management newly diagnosed type 1 diabetes [12], interruption of insulin treatment was not included among the primary aims.

In the recent past, some small trials have raised the possibility of mitigating the deterioration of beta cell function at the onset of type 1 diabetes using different approaches. In comparison with these trials, and judged by the $\mathrm{HbA}_{1} \mathrm{c}$ values during the follow-up period, we succeeded in achieving tight glycaemic control using intensive insulin therapy $[13,14]$. As has been stated recently, in intervention trials standard treatment with insulin therapy should aim to get $\mathrm{HbA}_{1} \mathrm{c}$ as close to normal as possible without causing hypoglycaemia, and this factor can influence outcome measures. It is well known that intensive insulin therapy can delay the loss of residual C-peptide secretion $[15,16]$, and the nearly-normal glycaemic control achieved in our trial could have mitigated and masked the potential beneficial effect of fusidin. Likewise, it can not be ruled out that an effect of fusidin could be unmasked if used with a greater number of patients, especially younger patients or those with a more rapid decline in beta cell function.
Our demonstration in the present study of the inability of fusidin to exert a favourable effect on the course of newly diagnosed type 1 diabetes is in striking contrast to preclinical studies carried out by ourselves and others using animal models of the disease, such as the NOD mouse [4], the diabetes-prone $\mathrm{BB}$ rat $[5,6]$ and the mouse made diabetic with MLDSZ [7], which all benefited from fusidin prophylaxis. The effect of fusidin in these three models of human type 1 diabetes was particularly encouraging for possible translation to the clinical setting, as inhibition of diabetes development in all these models is not achieved by the T-cell immunosuppressant CyA, which has shown a moderate effect in patients with type 1 diabetes [1]. In fact, whilst CyA prevents disease development in the NOD mouse [17] and the DP-BB rat [18], it worsens the course of the disease in the murine model of MLDSZ-induced diabetes [19].

In a more general context, the present data reinforce the limits of the rodent models of human type 1 diabetes, at least as in vivo tools for predicting immunopharmacological approaches for the treatment of the disease. As recently highlighted by Roep et al. [20, 21], the hundreds of compounds proven to be effective in delaying/preventing type 1 diabetes in these rodent models, while lacking substantial effect in the human disease counterpart, call for rethinking and re-evaluation of experimental immunotherapeutic approaches in the preclinical setting. Post-treatment follow-up studies are also important to ascertain the duration of the antidiabetogenic effect of tested compounds. Drugs whose action is rapidly reversed upon treatment interruption should not be worth considering for their use in human type 1 diabetes, as this would imply lifelong medication.

In summary, in our study, fusidin administered intermittently together with intensive insulin therapy was not more effective than intensive insulin therapy alone in preserving beta cell function in newly diagnosed type 1 diabetes. The outcome of our study does not, however, exclude a possible effect of FUS in delaying/preventing type 1 diabetes development if administered prophylactically to individuals at high risk of developing the disease. Because prolonged treatment with FUS was well tolerated and without haematological or biochemical side effects in the present study, we believe its use in small pilot trials in prediabetic individuals may still be worthy of consideration.

Acknowledgements We thank the nursery staff of the Endocrinology Unit of Hospital Clínic i Univeristari (Barcelona) for their technical assistance. We are indebted to Leo Pharma (Ballerup, Denmark) for providing us with sodium fusidate and placebo. This study was supported in part by grants from Instituto de Salud Carlos III, RCMN 03/08, RGDM 03/212.

\section{References}

1. Winter WE, Schatz D (2003) Prevention strategies for type 1 diabetes mellitus. Biodrugs 17:39-64 
2. Nicoletti F, Meroni PL, Bendtzen K (1996) Fusidic acid and insulin-dependent diabetes mellitus. Autoimmunity 24:187197

3. Bendtzen K, Diamant M, Faber V (1990) Fusidic acid, an immunosuppressive drug with functions similar to cyclosporin A. Cytokine 2:423-429

4. Nicoletti F, Zaccone P, Di Marco R et al (1995) Effects of sodium fusidate in animal models of insulin-dependent diabetes mellitus and septic shock. Immunology 85:645-650

5. Nicoletti F, Di Marco R, Morrone S et al (1994) Reduction of spontaneous autoimmune diabetes in diabetes-prone BB rats treated with the novel immunosuppressant fusidic acid. Effect on T-cell proliferation and production of interferon- $\gamma$. Immunology 81:317-321

6. Hageman I, Buschard K (2002) Antidiabetogenic effect of fusidic acid in diabetes prone BB rats: a sex-dependent organ accumulation of the drug is seen. Pharmacol Toxicol 91:123128

7. Nicoletti F, Di Marco R, Conget I et al (2000) Sodium fusidate ameliorates the course of diabetes induced in mice by multiple low doses of streptozotocin. J Autoimmun 15:395-405

8. Nicoletti F, Meroni PL, Lunetta M et al (1991) Sodium fusidate and increased remission rate of insulin-dependent diabetes mellitus. Lancet 337:1292

9. Nicoletti F, Nicoletti A, Giuffrida S et al (1998) Sodium fusidate in Guillain Barré syndrome: a case report. J Neurol Neurosurg Psychiatry 65:266-268

10. Nicoletti F, Patti F, Nicoletti A et al (1999) Sodium fusidate in steroid resistant relapses of multiple sclerosis. Mult Scler 5:377

11. Vidal J, Fernandez Balsells M, Sesmilo G et al (2000) Effects of nicotinamide and intravenous insulin therapy in newly diagnosed type 1 diabetes. Diabetes Care 23:360-364

12. Greenbaum C, Harrison LC (2003) Guideleines for interventions trials in subjects with newly diagnosed type 1 diabetes. Diabetes 52:1059-1065
13. Herold KC, Hagopian W, Auger JA et al (2002) Anti-CD3 monoclonal antibody in new-onset type 1 diabetes mellitus. $\mathrm{N}$ Engl J Med 346:1692-1698

14. Raz I, Elias D, Avron A et al (2001) Beta-cell function in new onset type 1 diabetes and immunomodulation with a heat-shock protein peptide (DiaPep277): a randomised, double-blind, phase II trial. Lancet 358:1749-1753

15. Madsbad S, Krarup T, Regeur L, Faber OK, Binder C (2001) Effects of strict blood glucose control on residual beta-cell function in insulin dependent diabetics. Diabetologia 20:530 534

16. The Diabetes Control and Complications Trial Research Group (1988) Effect of intensive therapy on residual beta-cell function in patients with type 1 diabetes in the diabetes control and complications trial. A randomized, controlled trial. Ann Intern Med 128:517-523

17. Mori Y, Suko M, Okudaira H et al (1986) Preventive effects of cyclosporin on diabetes in NOD mice. Diabetologia 29:244247

18. Like AA, Dirodi V, Thomas S, Guberski DL, Rossini AA (1984) Prevention of diabetes mellitus in the BB/W rat with cyclosporin-A. Am J Pathol 117:92-97

19. Sestier C, Odent-Pogu S, Bonneville M, Maurel C, Lang F, Sai $\mathrm{P}$ (1985) Cyclosporin enhances diabetes induced by low-dose streptozotocin treatment in mice. Immunol Lett 10:57-60

20. Roep BO, Atkinson M (2004) Animal models have little to teach us about type 1 diabetes: 1 . In support of this proposal. Diabetologia 47:1650-1656

21. Roep BO, Atkinson M, von Herrath M (2004) Satisfaction (not) guaranteed: re-evaluating the use of animal models of type 1 diabetes. Nat Rev Immunol 4:989-997 